\title{
ЛЮПИН УЗКОЛИСТНЫЙ: ВЛИЯНИЕ ГЕРБИЦИДОВ И УДОБРЕНИЙ НА ПРОДУКТИВНОСТЬ ЗЕЛЕНОЙ МАССЫ
}

\author{
V. L. Bopp, M. E. Danilov
}

\section{NARROW-LEAVED LUPINE: THE INFLUENCE OF HERBICIDES AND FERTILIZERS ON GREEN MASS PRODUCTIVITY}

Бопn Валентина Леонидовна - канд. биол. наук, доц., проректор по науке Красноярского государственного аграрного университета, г. Красноярск. E-mail: vl_kolesnikova@mail.ru Данилов Максим Евгеньевич - магистрант каф. почвоведения и агрохимии Красноярского государственного аграрного университета, г. Красноярск. E-mail: maksim_danilov_95@mail.ru

В полевом эксперименте на черноземах Красноярской лесостепи в условиях недостаточного влагообеспечения (ГТК за июнь-август 0,8) изучено влияние средств интенсификации производства (гербициды против однодольных и двудольных сорных растений, аммиачная селитра) на продуктивность зеленой массы люпина узколистного - новой культуры для региона. Посевы люпина сорта Белозерный 110 размещены в кормовом севообороте, предшественник - однолетние кормовые травы. Варианты опыта включали: 1) контроль (без применения средств интенсифрикации); 2) удобрения - N30; 3) гербициды («Лазурит», «Пилот» + «Квикстеп»); 4) удобрения - $N_{30}+$ гербициды («Лазурит», «Пилот» + "Квикстеп»). В агроценозе зафиксировано 10 видов сегетальной растительности, относящихся к биологической групnе яровые. Доминирующие сорняки - щирица (виды), просо (виды). Засоренность участка оценивается как сильная - перед применени-

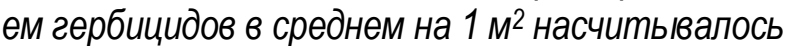
57 сорняков. Почвенньй гербицид «Лазурит» применили на 2-й день после посева люпина. Однако резкое повышение температуры воздуха и почвы, отсутствие осадков длительный период привели к снижению эфрфрективности препарата, соответственно возникла необходимость использовать баковую смесь гербицидов «Пилот» (против двудольных сорняков) + «Квикстеп» (против злаковых сорняков) по ве-
Bopp Valentina Leonidovna - Cand. Biol. Sci., Assoc. Prof., Vice-Rector for Science, Krasnoyarsk State Agrarian University, Krasnoyarsk.

E-mail: vl_kolesnikova@mail.ru

Danilov Maxim Evgenyevich - Magistrate Student, Chair of Soil Science and Agrochemistry, Krasnoyarsk State Agrarian University, Krasnoyarsk.

E-mail: maksim_danilov_95@mail.ru

гетации культуры. Биологическая эфффективность примененных гербицидов составила 71,9 \%. При сильной засоренности поля отклик растений люпина узколистного на гербициды превышает реакцию на аммиачную селитру. Использование аммиачной селитры в дозе $N_{30}$ не оказало положительного влияния на продуктивность зеленой массы люпина. Максимальная урожайность зеленой массы культуры 14,29 m/га получена на варианте с гербицидной защитой.

Ключевые слова: люпин, гербициды, удобрения, аммиачная селитра, продуктивность, зеленая масса, сорняки, щирица, просо сорнополевое, просо куриное.

In field experiment on chernozems of the Krasnoyarsk forest-steppe in the conditions of insufficient moisture providing (the State Customs Committee for June-August - 0.8) the influence of means of the intensification of production (herbicides against monocotyledonous and two-submultiple weed plants, ammonium nitrate) on the efficiency of green mass of lupine narrow-leaved - new culture for the region was studied. Lupine crops of Belozerny 110 variety were placed in forage crop rotation; the predecessors were annual forage grasses. The experiment options included: 1) control (without the use of intensification means); 2) fertilizers - $N_{30}$; 3) herbicides ('Lazurit', 'Pilot' + 'Quickstep'); 4) fertilizers - $\mathrm{N}_{30}+$ herbicides ('Lazurit', 'Pilot' + 'Quickstep'). 10 species of segetal 
vegetation belonging to spring biological group were recorded in the agrocenosis. Dominating weeds were amaranth (species) and millet (species). The site weediness was estimated as heavily polluted - before using the herbicides, there were 57 weeds per $1 \mathrm{~m}^{2}$ on average. The soil herbicide 'Lazurit' was applied on the $2^{\text {nd }}$ day after lupine sowing. However, sharp increase in air and soil temperature, the absence of precipitation for a long period led to the decrease in the preparation effectiveness, respectively, it was necessary to use a tank mixture of herbicides 'Pilot' (against dicotyledonous weeds) + 'Quickstep' (against cereal weeds) for the crop vegetation. Biological effectiveness of the applied herbicides made $71.9 \%$. When the field was heavily weeded, the response of blue lupine plants to herbicides exceeded the reaction to ammonium nitrate. The use of ammonium nitrate in a dose of $\mathrm{N}_{30}$ did not have a positive effect on the productivity of lupine green mass. The maximum yield of the green mass of the crop - 14.29 t/hectare was obtained on the variant with herbicide protection.

Keywords: lupine, herbicides, fertilizers, ammonium nitrate, efficiency, green mass, weeds, amaranth, weed millet, barnyard grass.

Введение. Стратегической задачей растениеводства и кормопроизводства является расширение посевов однолетних бобовых культур, увеличение их видового разнообразия, совершенствование сортового состава и технологии возделывания [1, 2]. В решении этой проблемы, а также биологизации земледелия большое значение имеет люпин [3]. Характеризуется ценными хозяйственно полезными признаками: высоким содержанием в семенах и листьях белка, полноценным аминокислотным составом, нерастрескиваемостью бобов при скашивании, высокой питательной ценностью и стабильной урожайностью зеленой массы и семян. В настоящее время имеются сорта с продолжительностью вегетационного периода 85-95 суток, что способствует продвижению границы выращивания на север. По данным [4], низкое содержание алкалоидов в зерне и зеленой массе люпина позволяет его использовать для производства различных видов кормов без ограничений.

Люпин узколистный (Lupinus angustifolius L.) новая для условий Красноярского края культура. Отсутствие исследований элементов технологии возделывания люпина узколистного в условиях региона, в том числе в части мероприятий по за- щите растений от вредных объектов, а также использования удобрений, оказывается значительным препятствием на пути внедрения этой культуры в производство.

Сорные растения являются постоянно действующим компонентом агросистем [5]. Биологической особенностью люпина является медленный темп роста надземной части до фазы бутонизации, поэтому люпин сильно угнетается сорняками [6], что и предопределяет значимость решения задачи по регулированию сорного компонента в люпиновых агроценозах.

Изучение системы защиты растений люпина от сорной растительности, отклик растений на внесение азотных удобрений в условия лесостепной зоны Красноярского края представляется актуальным.

Цель исследования: определить влияние гербицидов и минеральных удобрений на продуктивность зеленой массы люпина узколистного в условиях Красноярской лесостепи.

Задачи исследования: провести оценку видового состава сорной растительности на опытном участке, изучить биологическую эффрективность применения гербицидов на сорный компонент ценоза, определить влияние гербицидов и аммиачной селитры на морфометрические параметры сорных и культурных растений, сохранность растений к уборке и продуктивность зеленой массы люпина.

Объекты и методы исследования. Исследование проведено на опытном поле Красноярского ГАУ. Почвенный покров опытного участка представлен комплексом черноземов выщелоченных и обыкновенных мало-, среднемощных тяжелосуглинистого гранулометрического состава. Почвы характеризуются высоким и средним содержанием гумуса $(9,1-5,1 \%)$, нейтральной реакцией среды $\left(\mathrm{pH}_{\mathrm{H}_{2} \mathrm{O}}-6,6-6,8\right)$, высокой суммой обменных оснований (44-62 м-экв/100 г). В пахотном слое содержится нитратного азота 15-18 мг/кг; 141,9-233,0 мг/кг $\mathrm{P}_{2} \mathrm{O}_{5} ; 229,0$ $234,2 \mathrm{Mr} / \mathrm{Kг} \mathrm{K}_{2} \mathrm{O}$.

В целом вегетационный период года исследований характеризовался как засушливый ГТК (июнь - август) составил 0,8.

В эксперименте использовали люпин сорта Белозерный 110. В защите люпина узколистного применялись препараты, указанные в таблице 1. 
Перечень препаратов для комплексной защиты люпина

\begin{tabular}{|l|c|l|}
\hline \multicolumn{1}{|c|}{ Препарат } & $\begin{array}{c}\text { Норма расхода, } \\
\text { кг (л)/га (т) }\end{array}$ & \multicolumn{1}{c|}{ Сроки применения } \\
\hline ТМТД, ВСК & 6,0 & Протравливание семян \\
\hline Лазурит, СП & 1,0 & $\begin{array}{l}\text { Опрыскивание почвы до всходов культуры. Прикатыва- } \\
\text { ние кольчатыми катками }\end{array}$ \\
\hline Пилот, ВСК & 1,5 & Опрыскивание посевов до бутонизации культуры \\
\hline Квикстеп, МКЭ & 0,8 & $\begin{array}{l}\text { Опрыскивание посевов в фразу 2-6 листьев } \\
\text { у однолетних сорняков независимо от фазы развития } \\
\text { культуры }\end{array}$ \\
\hline
\end{tabular}

Для изучения влияния гербицидов и азотных удобрений на урожайность люпина узколистного был заложен полевой опыт по следующей схеме.

Варианты опыта: 1 - контроль (без применения средств интенсификации); 2 - удобрения $\mathrm{N}_{30} ; 3$ - гербициды («Лазурит», «Пилот» + «Квикстеп»); 4 - удобрения - $\mathrm{N}_{30}+$ гербициды («Лазурит», «Пилот» + «Квикстеп»).

Доза каждого из используемых препаратов соответствовала рекомендациям производителя. Аммиачная селитра внесена из расчета 30 кг/га действующего вещества по делянкам вариантов 2 и 4 перед посевом культуры.

Результаты исследования и их обсуждение. Люпин размещен в кормовом севообороте, предшественник - однолетние кормовые культуры.

Агротехника опыта: обработка почвы включала зяблевую обработку культиваторомплоскорезом на глубину 18 см, предпосевную культивацию на глубину 6-8 см. Независимо от варианта опыта весь посевной материал люпина перед посевом был обработан ТМТД, ВСК из расчета $6 \mathrm{л} / \mathrm{\tau}$. Посев семян сеялкой ССПН-1,6 на глубину 6 см, норма высева - 150 кг/га.

Засоренность участка оценивается как сильная. Гербицидная обработка Лазуритом проведена на 2-й день после посева люпина, остальные препараты были применены в начале фазы ветвления люпина при следующих погодных условиях: температура воздуха - $26,5{ }^{\circ} \mathrm{C}$, скорость ветра - 0,6-0,7 м/сек.

Повторность опыта трехкратная, размещение делянок систематическое, площадь опытной делянки 280 м², общая площадь опыта 3400 м².

Результаты оценки засоренности агроценоза люпина узколистного показали, что на опытном участке отмечено 10 видов сорной растительности, из них 3 вида (просо сорнополевое, просо куриное и овсюг) относятся к однодольным, остальные - к двудольным растениям. Все засорители агроценоза относятся к одной биологической группе - яровые.

Наибольшее распространение в посевах люпина получили сорные растения семейств Мятликовые и Амарантовые.

Возможность использования препарата «Лазурит» на посевах люпина ограничена примерно 5 днями (от посева семян до появления всходов). Опрыскивание почвы «Лазуритом» провели на 2-й день после посева люпина. В сложившихся погодных условиях в этот период (резкое повышение температуры воздуха и почвы, пересыхание верхнего слоя почвы) произошло частичное испарение препарата, кроме того, отсутствовали осадки в течение 2 недель, все это привело к снижению эффективности «Лазурита».

Так как для проведения эксперимента был выбран участок с сильной степенью засоренности (рис. 1), потребовалось применить гербициды по вегетации люпина. Состав сегетальной растительности включал как однодольные, так и двудольные сорняки, поэтому для гербицидной обработки была использована баковая смесь, состоящая из гербицидов «Пилот» и «Квикстеп».

В среднем на учетных делянках на 1 м² насчитывалось 57 сорных растений, доминирующими засорителями являются щирицы - запрокинутая и жминдовидная (28 шт/M²) и просо сорнополевое и куриное (22 шт/M²), остальные сорные растения встречаются в незначительном количестве - 1-2 шт/м² (табл. 2). 


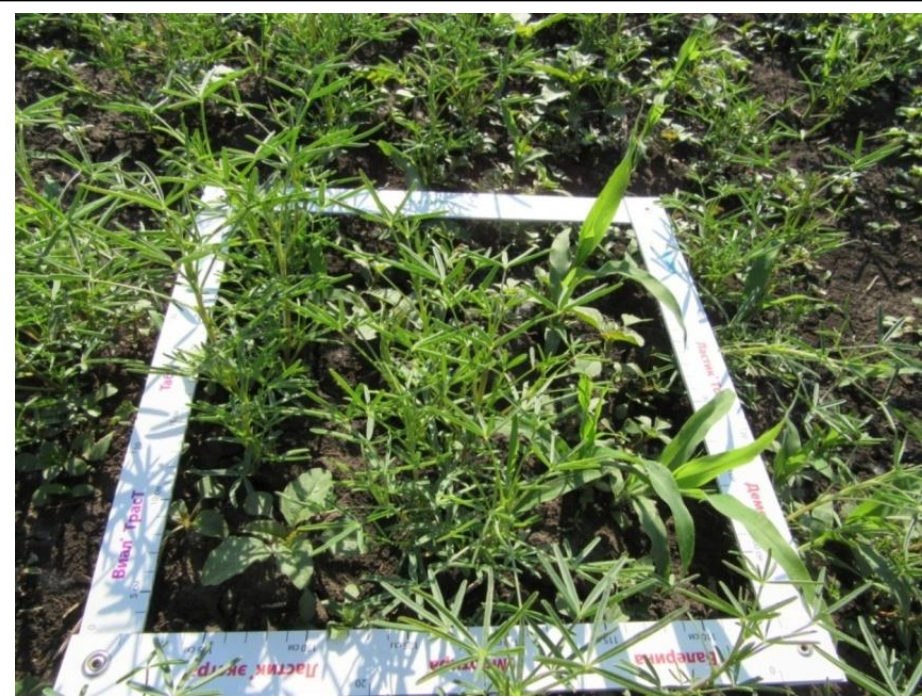

Puc. 1. Фитосанитарное состояние агроценоза люпина перед применением гербицидов по вегетации

Таблица 2

Результаты учета сорных растений в посевах люпина

\begin{tabular}{|l|c|c|c|}
\hline \multirow{2}{*}{ Вид сорного растения } & \multicolumn{2}{|c|}{ Кол-во сорных растений, шт/м² } & $\begin{array}{c}\text { Эффрект } \\
\text { от защиты, \% }\end{array}$ \\
\cline { 2 - 3 } & без обработки & с обработкой & 46,2 \\
\hline Щирица запрокинутая & 13 & 7 & 40,0 \\
\hline Щирица жминдовидная & 15 & 9 & 100 \\
\hline Горец вьюнковый & 1 & 0 & 100 \\
\hline Марь остистая & 2 & 0 & 100 \\
\hline Марь белая & 1 & 0 & 100 \\
\hline Подмаренник цепкий & 1 & 0 & 100 \\
\hline Просвирник обыкновенный & 1 & 0 & 100 \\
\hline Просо сорнополевое & 10 & 0 & 100 \\
\hline Просо куриное & 12 & 0 & 100 \\
\hline Овсюг & 1 & 0 & 71,9 \\
\hline Итого & 57 & 16 & \\
\hline
\end{tabular}

Обработка посевов люпина баковой смесью гербицидов позволила полностью уничтожить злаковые сорняки, также чувствительные к препарату оказались горец вьюнковый, марь остистая, марь белая, подмаренник цепкий, просвирник обыкновенный.

Чувствительность щирицы (виды) к метаметрону, действующему веществу «Пилота», значительная, биологическая эфффективность препарата по отношению к данному сорняку превышает $90 \%$, однако в нашем опыте она составила $40-46 \%$.

Действующее вещество «Пилота» проникает в сорное растение преимущественно через корни, его использование позволяет задержать появление второй «волны» сорняков. При этом
«Пилот» подавляет двудольные сорняки на ранней стадии их развития. Ценоз щирицы состоял из растений разных фаз развития - от всходов до 5-6 настоящих листьев. «Квикстеп» применяется против злаковых сорняков в достаточно широком диапазоне - от всходов до ветвления культурного растения, что и обусловило эфффективность препарата.

Фитосанитарное состояние посевов люпина в фазе сизых бобов на контрольных делянках и на делянках с применением гербицидов представлено на рисунках 2, 3 .

Применение мероприятий по химической защите растений положительно повлияло на сохранность растений люпина к уборке (рис. 4). 


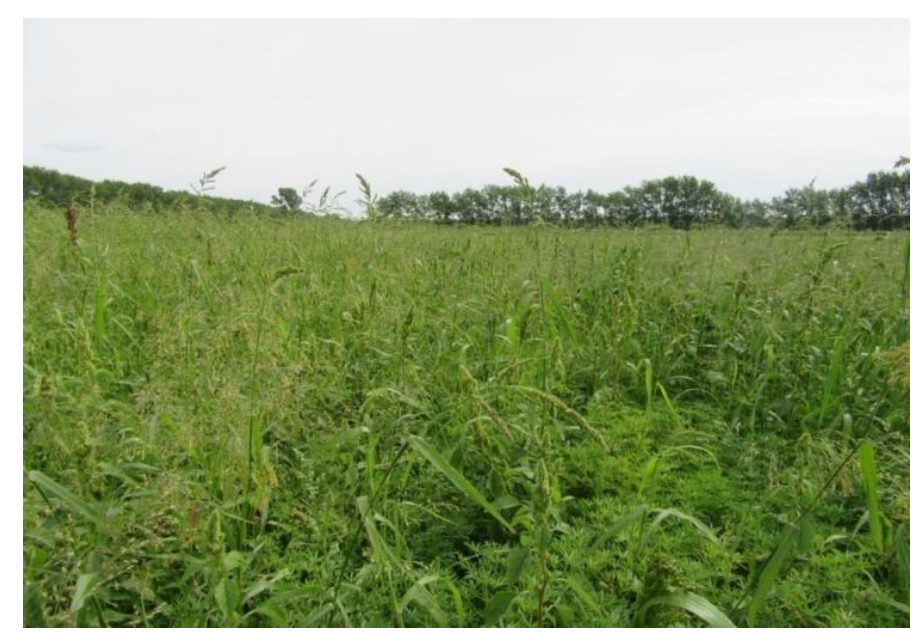

Puс. 2. Фитосанитарное состояние посевов люпина узколистного без применения гербицидов

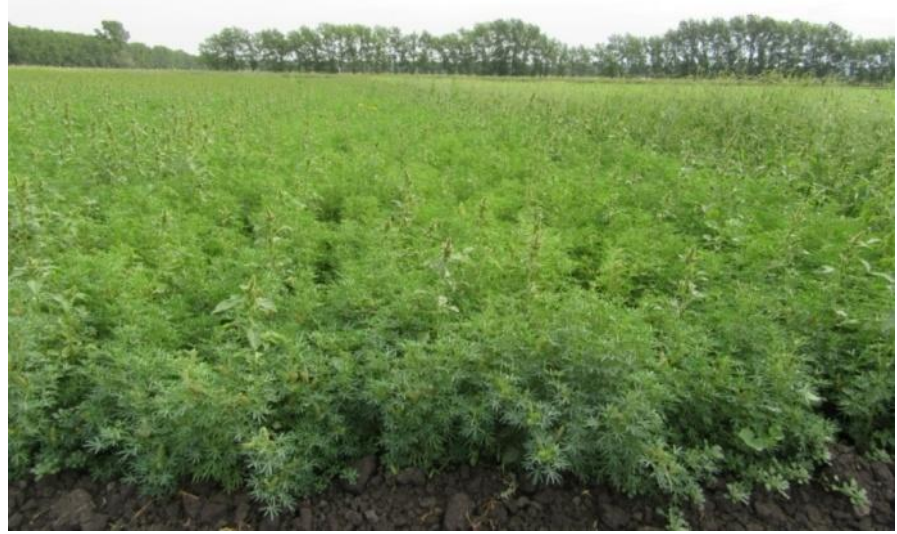

Puc. 3. Влияние гербицидов на фритосанитарное состояние посевов люпина узколистного

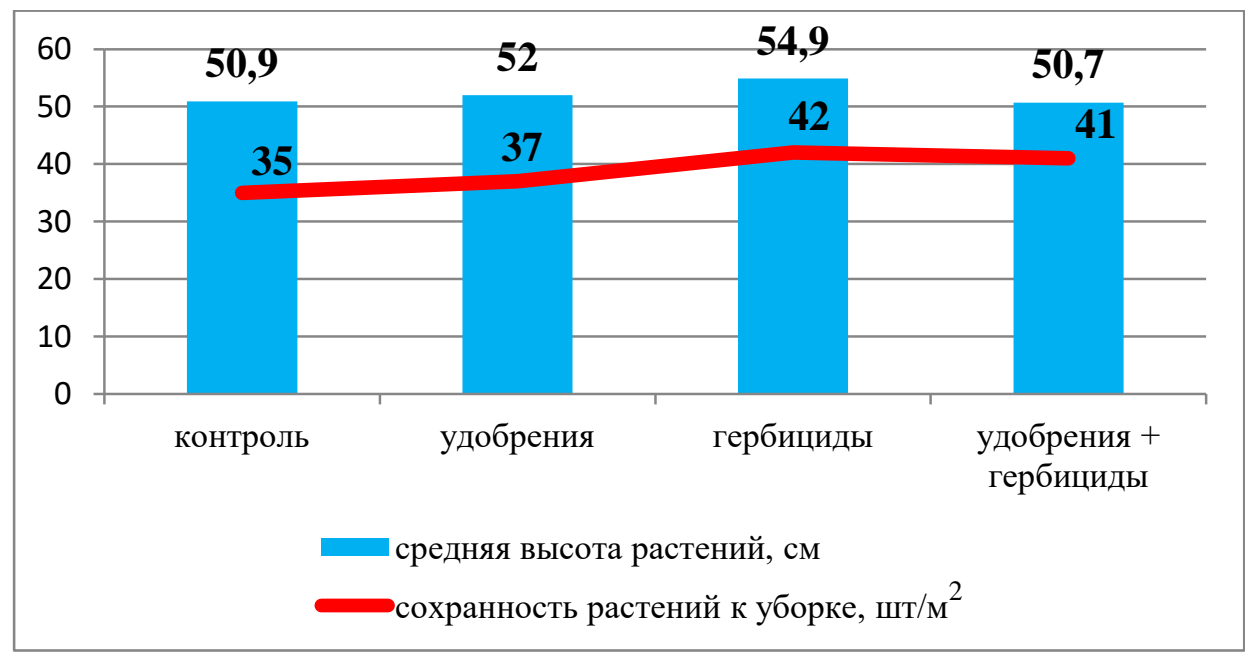

Puс. 4. Влияние средств интенсификации на высоту растений люпина и сохранность растений к уборке 
Средняя высота растений люпина на всех экспериментальных участках превышала $50 \mathrm{~cm}$, значительной разницы между вариантами опыта не наблюдалось, амплитуда показателя варьировала от 51 (контроль, удобрения + средства защиты растений) до 55 см (средства защиты растений).
Рассматривая максимальные значения высоты культурных и сорных растений по вариантам опыта (рис. 5), отметим, что самые высокие растения люпина на всех экспериментальных делянках были на уровне 64-66 см, т. е. сформировались практически одинаковых размеров.

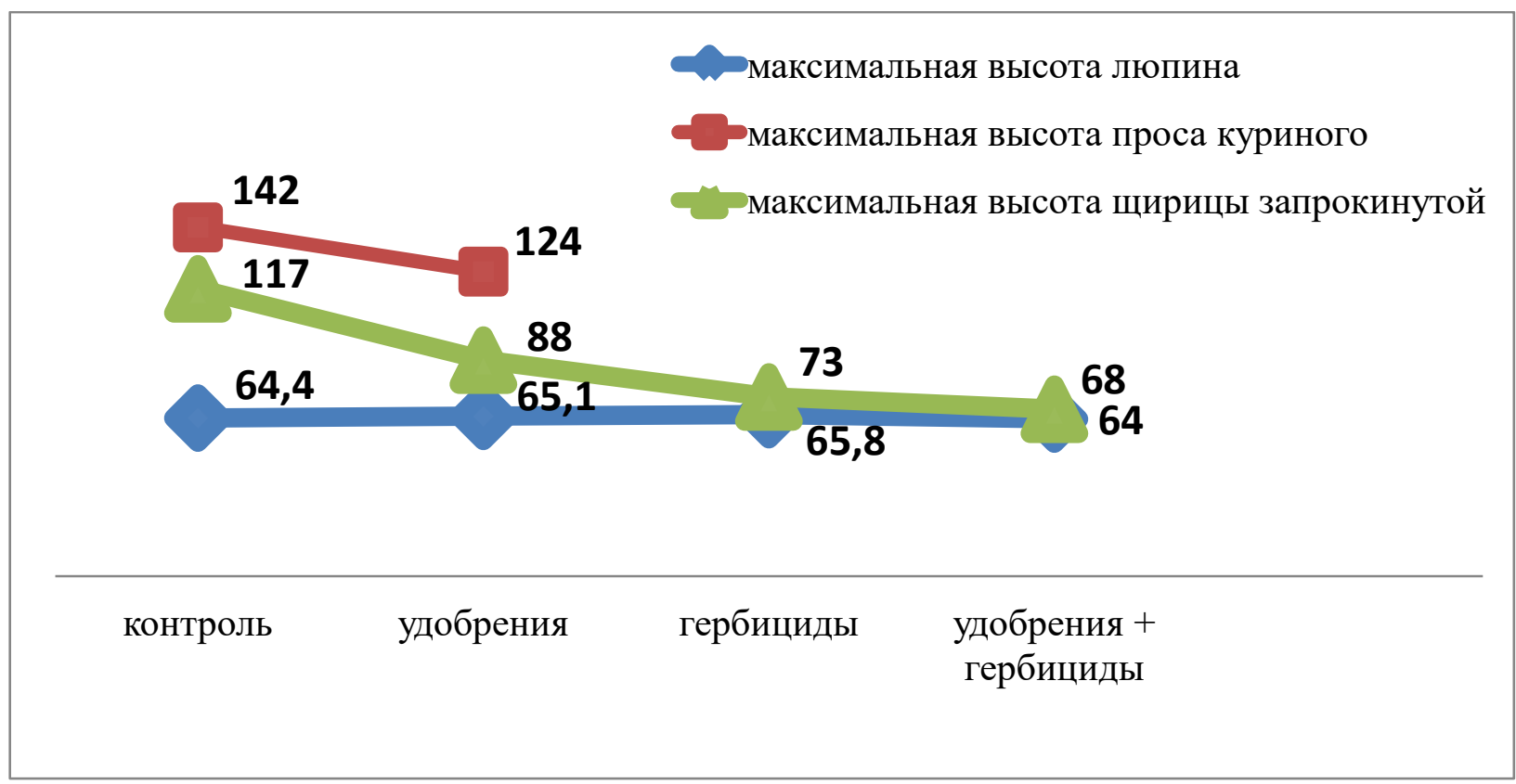

Puс. 5. Влияние гербицидов и азотных удобрений на максимальную высоту культурных и сорных растений, см

Наиболее высокие сорняки отмечены на контрольном варианте: высота проса куриного 142 см, щирицы запрокинутой - 117 см.

К уборке на зеленую массу общий вес сырой биомассы культурных и сорных растений на контрольном варианте (без применения средств интенсификации производства) составил 13,54 т/га (табл. 3), из них вес люпина - 6,47 т/га, доля сорного компонента - 7,07 т/га, или 52,2 \%.
Внесение удобрений в дозе $\mathrm{N}_{30}$ не оказало положительного влияния на формирование биомассы агроценоза люпина. По мнению [7], азотные удобрения в малых и средних дозах снижают активность азотфиксации и не повышают урожайность бобовых культур, что подтверждается и нашими исследованиями: наблюдается тенденция увеличения фритомассы сорной растительности и снижение веса растений люпина.

Таблица 3

Доля сорного компонента в посевах люпина в зависимости от уровня интенсификации

\begin{tabular}{|c|c|c|c|c|c|c|c|c|}
\hline \multirow{3}{*}{ Вариант } & \multirow{3}{*}{$\begin{array}{c}\text { Общий вес } \\
\text { биомассы, } \\
\text { т/га }\end{array}$} & \multicolumn{2}{|c|}{ В т. ч. вес, т/га } & \multicolumn{4}{|c|}{ 土 к контролю } & \multirow{3}{*}{$\begin{array}{c}\text { Доля сорного } \\
\text { компонента, \% }\end{array}$} \\
\hline & & \multirow{2}{*}{ сорняков } & \multirow{2}{*}{ люпина } & \multicolumn{2}{|c|}{ сорняки } & \multicolumn{2}{|c|}{ люпин } & \\
\hline & & & & т/га & $\%$ & т/га & $\%$ & \\
\hline Контроль & 13,54 & 7,07 & 6,47 & - & & - & & 52,22 \\
\hline Удобрения & 12,36 & 7,35 & 5,01 & $+0,28$ & $+3,96$ & $-1,46$ & $-22,56$ & 59,47 \\
\hline Гербициды & 16,15 & 1,86 & 14,29 & $-5,21$ & $-73,69$ & $+7,82$ & $+120,86$ & 11,52 \\
\hline $\begin{array}{l}\text { Удобрения + } \\
\text { гербициды }\end{array}$ & 13,98 & 1,02 & 12,96 & $-6,05$ & $-85,57$ & $+6,49$ & $+100,31$ & 7,29 \\
\hline
\end{tabular}


Сорные растения обладают более развитой корневой системой и быстрыми темпами роста, потребляют из почвы большое количество минеральных веществ. Поэтому минеральные удобрения способствовали увеличению фитомассы сорняков.

Использование гербицидов позволило существенно снизить засоренность посевов, вес зеленой массы люпина увеличился в 2,2 раза по отношению к контрольному показателю, а вес сорняков в общей фитомассе сократился в 3,8 раза, что обеспечило максимальную продуктивность агроценоза (16,15 т/га) и повысило кормовую ценность зеленой массы за счет сокращения доли сорных растений.

Выводы. Почвенно-климатические условия лесостепной зоны Красноярского края позволяют возделывать люпин узколистный на зеленую массу, для повышения продуктивности агроценоза люпина необходимо адаптировать элементы технологии к требованиям культуры.

При высокой степени засоренности поля однолетними однодольными и двудольными сорными растениями биологическая эфффективность применения баковой смеси гербицидов «Квикстеп» и «Пилот» получена на уровне $72 \%$.

Урожайность зеленой массы люпина зависит от использования гербицидов. Лучшая результативность получена на варианте с опрыскиванием посевов баковой смесью гербицидов «Квикстеп» и «Пилот» без внесения минеральных удобрений - урожайность зеленой массы составила 14,29 т/га.

\section{Литература}

1. Бени В.А., Кашеваров Н.И., Демарчук Г.А. Полевое кормопроизводство в Сибири / РАСХН, Сиб. отд-ние, СибНИИ кормов. Новосибирск, 2001. С. 51.

2. Аветисян А.Т., Данилова В.В., Данилов Н.В. и др. Технология возделывания кормовых культур в Красноярском крае: руководство. Красноярск, 2012. С. 29.

3. Белоус Н.М., Ториков В.Е., Мельникова О.В. Зернобобовые культуры и однолетние бо- бовые травы: биология и технология возделывания. Брянск, 2010. 151 с.

4. Такунов И.П., Слесарева Т.Н., Лукашевич М.И. и др. Перспективная ресурсосберегающая технология производства люпина: метод. рекомендации / Росинформагротех. М., 2011.76 c.

5. Пурлаур В.К., Трубников Ю.Н., Бутковская Л.К. и др. Химическая защита зерновых культур в Красноярском крае: метод. рекомендации. Красноярск, 2009.

6. Вавилов П.П., Гриценко В.В., Кузнецов В.С. и др. Растениеводство / под ред. П.П. Вавилова. М.: Агропромиздат, 1986. С. 189.

7. Посыпанов Г.С. Биологический азот. Проблемы экологии и растительного белка. М., 1993. С. 268.

\section{Literatura}

1. Benc V.A., Kashevarov N.I., Demarchuk G.A. Polevoe kormoproizvodstvo v Sibiri / RASHN, Sib. otd-nie, SibNII kormov. Novosibirsk, 2001. S. 51.

2. Avetisjan A.T., Danilova V.V., Danilov N.V. i dr. Tehnologija vozdelyvanija kormovyh kul'tur $v$ Krasnojarskom krae: rukovodstvo. Krasnojarsk, 2012. S. 29.

3. Belous N.M., Torikov V.E., Mel'nikova O.V. Zernobobovye kul'tury i odnoletnie bobovye travy: biologija i tehnologija vozdelyvanija. Brjansk, 2010. $151 \mathrm{~s}$.

4. Takunov I.P., Slesareva T.N., Lukashevich M.I. i dr. Perspektivnaja resursosberegaju-shhaja tehnologija proizvodstva ljupina: metod. Rekomendacii / Rosinformagroteh. M., 2011. 76 s.

5. Purlaur V.K., Trubnikov Ju.N., Butkovskaja L.K. i dr. Himicheskaja zashhita zernovyh kul'tur v Krasnojarskom krae: metod. rekomendacii. Krasnojarsk, 2009.

6. Vavilov P.P., Gricenko V.V., Kuznecov V.S. I dr. Rastenievodstvo / pod red. P.P. Vavilova. M.: Agropromizdat, 1986. S. 189.

7. Posypanov G.S. Biologicheskij azot. Problemy jekologii i rastitel'nogo belka. M., 1993. S. 268. 